\title{
HANDBOOK OF PRECISION ENGINEERING
}




\section{HANDBOOK OF PRECISION ENGINEERING}

Volume 1 Fundamentals

Volume 2 Materials

Volume 3 Fabrication of Non-metals

Volume 4 Physical and Chemical Fabrication Techniques

Volume 5 Joining Techniques

Volume 6 Mechanical Design Applications

Volume 7 Electrical Design Applications

Volume 8 Surface Treatment

Volume 9 Machining Processes

Volume 10 Forming Processes

Volume 11 Production Engineering

Volume 12 Precision Measurement 
Philips Technical Library

\section{HANDBOOK OF \\ PRECISION ENGINEERING}

Edited by A. Davidson

\section{Volume 10 Forming Processes}

Macmillan Education 
Original Dutch edition (C) N. V. Philips' Gloeilampenfabrieken, Eindhoven, 1971

English edition (C) N. V. Philips' Gloeilampenfabrieken, Eindhoven, 1974

Softcover reprint of the hardcover 1st edition 1974 978-0-333-11830-6

All rights reserved. No part of this publication may be reproduced or transmitted, in any form or by any means, without permission.

ISBN 978-1-349-81591-3 ISBN 978-1-349-81589-0 (eBook)

DOI 10.1007/978-1-349-81589-0

First published in English by

THE MACMILLAN PRESS LTD

London and Basingstoke

Associated companies in New York Melbourne

Dublin Johannesburg and Madras

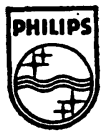

\section{PHILIPS}

Trademarks of N. V. Philips' Gloeilampenfabrieken 


\section{Foreword}

During the last twenty or thirty years, precision engineering, although not strictly a separate branch of engineering, like shipbuilding and the aircraft industry, has emerged as a specialized technology, involving methods and ideas foreign to conventional mechanical engineering.

Precision-engineered parts (or fine mechanisms, as they are often termed) are very often of limited size, and vary in quantity from one-off to very long runs. But they don't have to be small, of course. For example, the driving mechanism of an observatory telescope, which is fairly large, has to be designed and constructed with extreme precision, whilst an ordinary watch, which is quite small by comparison, is relatively crude as far as tolerances are concerned.

Examples of fine mechanisms are to be found in telecommunications equipment; optical apparatus such as microscopes and comparators, as well as cameras and projectors; office machines like typewriters, accounting and calculating machines; various toys of a technical nature, mentioned because of their often ingenious design and the consummate tool-making that goes into them; electric shavers; and various electronic equipment used in the home.

There is a need, in industry and in training schools, for a handbook such as this, covering, in a convenient form, the different subjects that are related to the design of fine mechanisms. Much of the material dealt with is not new in itself, of course, but, because it is presented specifically in the context of precision engineering, it should be invaluable to designers, manufacturers and users of precision-engineered parts.

The authors, each of whom is a specialist in his own field, do not claim to have covered the individual subjects fully in the chapters assigned to them. They have presented the main features as clearly as possible, and provided international references from which the reader can obtain more details as required.

The handbook is divided into eleven parts, of which Volume 1 deals with the general principles to be observed when designing a product, and Volume 2 with the materials available. Theoretical and practical data useful to designers and draughtsmen is given.

Volumes 3-5 and 8-10 discuss production techniques, and production staff will find them to contain comprehensive information on production methods and plant. Volumes 6, 7,11 and 12 deal with the practical design of precision-engineered products, and the equipment and components required for this purpose. Designers, manufacturers and users can all profit from them.

The editor would like to take this opportunity of thanking the authors and all who have helped to produce the handbook. 


\section{Contents}

Introduction

A. Davidson xii

Chapter I Shearing Processes

M. L. L. P. J. Ledel

1.1 Introduction

1.2 Shearing technology

1.2.1 Punching

1.2.2 Clearance between punch and die

1.2.3 Punch force and punch work done

1.2.4 Stripping force

1.2.5 Effects of contraction and punch and die clearance upon product dimensions

1.2.6 Blanking synthetic resin bonded paper

1.3 Cutting or shearing tools

1.3.1 Simple blanking or piercing dies

1.3.2 Follow or progressive dies

1.3.3 Cropping and piercing dies

1.3.4 Die sets

1.3.5 Compound blanking and piercing dies

1.3.6 Steel rule dies

1.3.7 Rubber tools

1.3.8 Planishing tools

1.4 Practical design details of dies and die members

1.4.1 Fastening a spring loaded guide plate to the top die

1.4.2 Embedding guide plates and punch plates

1.4.3 Sectional dies and punches

1.4.4 Use of hard metal in dies

1.4.5 Use of Ferro-TiC in cutting tools

1.4.6 Die bores made by spark erosion

1.4.7 Minimum pierceable hole diameter

1.4.8 Stock discharge through the die

1.4.9 Various design details of a progressive or follow die

1.4.10 Safeguarding dies in operation

1.5 Presses for blanking and piercing

1.5.1 Eccentric presses with open fronted C-frame

1.5.2 Double sided presses

1.5.3 High speed presses 
1.6.1 Technology

1.6.2 Special shaving press

1.7 Fine blanking and piercing

1.7.1 Technology

1.8 Cold fow shearing

1.9 Shearing machines

1.9.1 Technology

1.9.2 Machines

1.10 Press auxiliaries

1.11 Applications

1.12 Safety devices

Chapter 2 Bending and Drawing Operations

S. von Marinelli

A. Davidson

2.1 Introduction

2.2 Bending

2.2.1 Technology

2.2.2 Tools and machines

2.2.3 Applications

2.3 Wireforming

2.3.1 Technology

2.3.2 Tools and machines

2.3.3 Applications

2.4 Spinning

2.4.1 Technology

2.4.2 Tools and machines

2.4.3 Applications

2.5 Deep drawing

2.5.1 Technology

2.5.2 Tools and machines

2.5.3 Modes of deep drawing

2.5.4 Applications 
2.6 High velocity forming

2.6.1 Explosive forming

2.6.2 Electrohydraulic forming

2.6.3 Pneumatic-mechanical forming

2.6.4 Electromagnetic forming

Chapter 3 Flow Forming

H. A. V. Lieshout

H. Swets

A. Davidson

3.1 General introduction

3.2 General technology

3.2.1 Materials

3.2.2 Compressive forces

3.2.3 Lubrication

3.2.4 Classification of processes

3.2.5 Tools

3.2.6 Machines

\subsection{Upsetting}

185

3.3.1 Technology

3.3.2 Tools and machines

3.3.3 Applications

3.4 Pressing and coining

195

3.4.1 Technology

3.4.2 Tools and machines

3.4.3 Applications

3.5 Impact extrusion

3.5.1 Technology

3.5.2 Tools and machines

3.5.3 Applications

3.6 Bar or sectional extrusion

224

3.6.1 Technology

3.6.2 Tools and machines

3.6.3 Applications

3.7 Rolling

3.7.1 Technology

3.7.2 Tools and machines

3.7.3 Applications

H.P.E. $10-1$ * 
3.8.1 Hobbing

3.8.2 Swaging and rotary swaging

3.8.3 Wire drawing

3.8.4 Hydrostatic extrusion

3.8.5 Rolling

3.8.6 Straightening

Chapter 4 Powder Metallurgy

F. Magendans

4.1 Introduction

4.2 Technology

4.2.1 Methods of powder manufacture

4.2.2 Powder properties

4.3 Compacting metal powders

4.3.1 Technology

4.3.2 Machines

4.4 Other methods of compacting

4.4.1 Slip casting

4.4.2 Extrusion of metal powders

4.4.3 Hydrostatic compaction

4.4.4 Powder rolling

4.4.5 High speed compaction

4.5 Dies for pressing structural parts

4.6 Sintering

4.6.1 Technology

4.6.2 Composite materials

4.6.3 Equipment

4.7 Postsintering processes and finishing operations

4.7.1 Postsintering processes

4.7.2 Finishing operations on sintered material

4.8 Tolerancing structural parts

4.9 Properties of sintered products

4.9.1 Mechanical properties

4.9.2 Physical properties 

4.10.1 Structural parts
4.10.2 Bearing materials
4.10.3 Filter materials
4.10.4 Friction materials
4.10.5 Compact materials
4.10.6 Hard metal
4.10.7 Ferro-TiC
4.10.8 Sintered tool shanks

$\begin{array}{ll}\text { Chapter } 5 \text { Fluid Forming Processes } & \text { L. B. J. Janssen }\end{array}$

5.1 Introduction 331

5.2 Physical behaviour of metals during solidification 332

5.2.1 Shrinkage

5.2.2 Gas release

5.2.3 Segregation

5.2.4 Heat extraction

5.3 Casting design

5.3.1 Introduction

5.3.2 Structural design of castings

5.3.3 Hints on design with a view to fettling

5.4 Casting techniques in general use

5.4.1 Sand casting

5.4.2 Shell moulding

5.4.3 Investment casting

5.4.4 Gravity die casting

5.4.5 Pressure die casting

5.4.6 Relative possibilities of casting methods described so far

5.5 Special casting methods

5.5.1 Continuous casting

5.5.2 Decanting process

5.5.3 Centrifugal casting

5.5.4 Dual metal casting

5.5.5 Melt hobbing

5.6 Variants of the general purpose casting methods

5.7 Foundry metals

5.7.1 Introduction

5.7.2 Classification

5.7.3 Further particulars of the foundry metals 
5.9 Aftertreatment of castings

5.9.1 Heat treatments

5.9.2 Fettling

5.10 Inspection of castings

5.10.1 Dimensional variations

5.10.2 Surface defects

5.10.3 Internal flaws

5.10.4 Mechanical properties

5.10.5 Chemical composition

5.10.6 Corrosion resistance tests

5.10.7 Technological fitness tests

5.11 Ordering castings

Index 


\section{Introduction}

\section{A. DAVIDSON}

Processes of metal forming without stock removal are of essential importance particularly to the precision engineering industry and mainly as an economical means of mass production.

Major advances in the mechanisation of these processes have led to the development of very complex machines whilst the tools have had to be made exceptionally accurate and are often of intricate design. These are discussed in considerable detail throughout the various chapters, chiefly because users are more than likely to make their own tools, but order the machines from specialists. The essential features of the machines are outlined so that the reader will be able to discuss them knowledgeably with his supplier and thus solve any problems which may arise.

The first chapter deals with shearing operations, the application and development of which have been given considerable impetus by the vast expansion of industrial production and consequent demand for products in more or less large quantities. The object of shearing processes is to enable those with enough knowledge of them and of all the available punches and dies to decide how best to design and manufacture a given product at least cost.

Bending and drawing operations are discussed in chapter 2 . They are used mainly to make products from strip or sheet material, or wire, and include high speed forming as well as more elementary sheet metal work like spinning and deep drawing. Although at present still employed mostly for very large workpieces these processes are very likely to be adopted shortly for precision engineering purposes as well.

Cold forging (chapter 3 ) has become increasingly prominent amongst manufacturing processes of late. It offers considerable scope for economy as compared with more conventional methods. The processes employed overlap to such an extent that the machine and tool descriptions apply to several of them. These forming processes are mainly characterised by a high degree of deformation, that is by the material reaching its final shape through pronounced plastic flow under severe compressive stress.

Chapter 4 deals with sintering (powder metallurgy), an old established way of making metal objects, yet one quite recently cultivated for the large scale manufacture of special precision engineered products as an economical alternative to far more expensive methods of making the parts. The other attendant operations such as trimming and finishing are also described.

Although fluid forming techniques stem originally from the heavier industries they are also used extensively for the manufacture of relatively small 
products, albeit with some modification so that they should not be considered primarily in terms of the conventional casting of steel in sand. The relevant chapter goes into some detail concerning the treatment of suitable foundry metals, upon which the success of a casting largely depends.

Each chapter deals with the technological aspects first, followed by the tools and machines and finally a variety of applications.

For information as to the physical properties of the materials see Vol. 2 (materials).

The symbols employed are those of the rational (ISO) system as defined in Vol. 1, chapter 1 . 